Drivers for micrometer-scale deformation and progressive rock mass damage in a deglaciating rock slope - insights from subsurface in-situ monitoring

Other Conference Item

Author(s):

Hugentobler, Marc; Aaron, Jordan; Loew, Simon (i)

Publication date:

2021

Permanent link:

https://doi.org/10.3929/ethz-b-000510394

Rights / license:

Creative Commons Attribution 4.0 International

Originally published in:

EGUsphere, https://doi.org/10.5194/egusphere-egu21-5192 
EGU21-5192, updated on 18 Oct 2021

https://doi.org/10.5194/egusphere-egu21-5192

EGU General Assembly 2021

(c) Author(s) 2021. This work is distributed under

the Creative Commons Attribution 4.0 License.

\section{Drivers for micrometer-scale deformation and progressive rock mass damage in a deglaciating rock slope - insights from subsurface in-situ monitoring}

Marc Hugentobler, Jordan Aaron, and Simon Loew

ETH Zurich, Geological Institute, Earth Sciences, Zürich, Switzerland (marc.hugentobler@erdw.ethz.ch)

Large rock slopes instabilities form over long timescales through progressive rock mass strength weakening of initially stable slopes. Progressive rock mass damage is driven by environmental loads and is thus strongly dependent on the local setting and environmental conditions of the rock slope, which can vary over time. It is often assumed that the strong variations of the thermal and hydraulic boundary conditions during deglaciation in combination with unloading due to ice downwasting cause enhanced rates of rock mass damage. However, in-situ observations to quantify deformation, damage and the relevance of different drivers in such environments are rare. This presentation is related to the contribution of Oestreicher et al., presenting in the same session, addressing similar questions, but at different scales and based on different field data and analysis.

In this contribution we analyze continuous pore pressure, temperature and micrometer-scale deformation time series from a subsurface monitoring system comprised of three, $50 \mathrm{~m}$ deep, highly instrumented boreholes in a crystalline rock slope which is located beside the rapidly retreating glacier tongue of the Great Aletsch Glacier (Switzerland). We compare high-resolution reversible and irreversible deformation signals with potential drivers, including locally measured pore pressure fluctuation, rock temperature variations, and nearby earthquakes. We show that shallow (10 - $15 \mathrm{~m}$ deep) deformations in our rock slope are dominated by thermo-mechanical forcing, whereas deformation measured below this depth is mainly driven by hydro-mechanical effects related to pore pressure fluctuations. Both reversible deformation and irreversible damage events occur more frequently during the snow-free summer season, when we observe higher dynamics in thermal and hydraulic boundary conditions. In our 2.5 years long time series, we do not find any significant deformation event coinciding with a nearby earthquake. Additionally, we discuss differences in the deformation signal with respect to the stability state and the rock mass quality at the different monitoring locations. Also, we assess longer term impacts of glacier retreat and ice downwasting on rock slope deformation and damage. Such information is critical for an improved understanding and quantification of factors contributing to the formation of paraglacial rock slope instabilities. 